\title{
GIRA DE SANTO E CABOCLO NO "RECANTO DE OGUM" DE PAI KANZILÊ - IMAGENS DE UM TERREIRO NAGÔ DA CIDADE DE SOURE (MARAJÓ/PARÁ)
}

\author{
Wladirson R. da S. Cardoso ${ }^{1}$
}

As imagens reunidas neste ensaio constituem o acervo de fotos registradas e utilizadas em tese de doutoramento, intitulada "Para além da juventude - "antropologia da experiência" e do "modo de vida gay" de homossexuais masculinos em processo de envelhecência da cidade de Soure (Marajó/Pará)", realizada no e defendida pelo Programa de Pós-Graduação em Antropologia da Universidade Federal do Pará (PPGA/UFPA), entre os anos de 2010 e 2014, sob a supervisão e orientação do Prof. Dr. Ernani Pinheiro Chaves.

Neste sentido, tais imagens resultam de trabalho de campo, que, no contexto da pesquisa etnográfica, permeia a inserção do antropólogo em um outro universo simbólico e material e, consequentemente, norteia sua interpretação e descrição - as quais se materializam em etnografias da realidade vivida de sujeitos e grupos.

Em linhas gerais, é possível caracterizar a experiência e vivência de campo aqui apresentadas como uma múltipla possibilidade de reconstrução epistemológica da questão do envelhecimento gay, em vista de um deslocamento de olhar que descentraliza o debate dos grandes núcleos urbanos e citadinos para um outro contexto existencial de uma cidade localizada, por sua vez, no "interior” da Amazônia Marajoara.

As imagens produzidas e aqui expostas a um público de leitores e amantes da Antropologia dizem respeito ao Terreiro "Recanto de Ogum", de Pai Kanzilê, que, na condição de homossexual em processo de envelhecimento - ou envelhecente (!) desempenha um papel social relevante em sua comunidade, a medida que consegue desconstruir a lógica da heternormatividade e das relações de gênero e sexualidade, quando, investido de poder sacerdotal, possui o respeito total de sues filhos de santo, vizinhos e convidados. Esse respeito se torna reverência e devoção, exatamente no momento em que Kanzilê, "virado em Oxum", isto é, a deusa mãe do amor (na cosmologia das religiões de matrizes africanas) desce à terra, na festa de e abençoa seus fieis com o seu axé...

Como se pode ver, então, o presente ensaio denota as convergências de algumas linhas de força - política-religião-e-homossexualidade - que, por sua vez, asseguraram a etnografia de duas giras - uma de Santo e outra de Caboclo - num mesmo terreiro de Umbanda e Candomblé, precisamente localizado em um bairro na periferia de Soure, numa paisagem

\footnotetext{
${ }^{1}$ Doutor em Antropologia Social e Pós-Doutor em Currículo. Docente no CCSE/DFCS/PPGCR - UEPA e NEB/PPEB - UFPA. E-mail: wladirson.cardoso@gmail.com
} 
bucólica e pitoresca, nas cercanias do rio Paracauari. O ensaio fotográfico em tela apresenta a dinâmica de organização e funcionamento pulsantes do Recanto de Ogum, qual seja, um Terreiro de Nação Nagô, situado numa área de ocupação popular, distante da vida comercial e relativamente agitada do cotidiano sourense, caracterizado pela atividade comercial, presença de hotéis de médio porte, bares e alguns restaurantes, dados à disposição do turismo veranista. O lugar pertence, tal qual já se destacou acima, pertence ao Pai Kanzilê que, na condição de homossexual envelhecente e de líder religioso, contribuiu significativamente para a compreensão do cotidiano e do modo de vida gay no contexto de Soure, em particular no que respeita ao lugar que ele mesmo ocupa no interior do seu mundo de Caboclos e Orixás.

Em tempo, destaco, ainda, que as imagens deste ensaio se inscrevem nos horizontes de uma Antropologia Visual e da Imagem que, em razão da natureza mesma do trabalho etnográfico desenvolvido durante o período de doutoramento - e anteriormente explicitado correlaciona-se a uma Antropologia da(s) Sexualidade(s), contribuindo para uma nova tentativa de interpretação e reflexão acerca da diferença no campo da diversidade e performatividade de gênero e sexualidade. Mais uma vez, portanto: o ensaio que ora se apresenta é fruto de uma etnografia das práticas e representações da homossexualidade masculina envelhecente e suas respectivas nuances expressas mediante resultado de observação participante e imersão no tempo-espeço da pesquisa e do presente do Recanto de Ogum de Pai Kanzilê. 


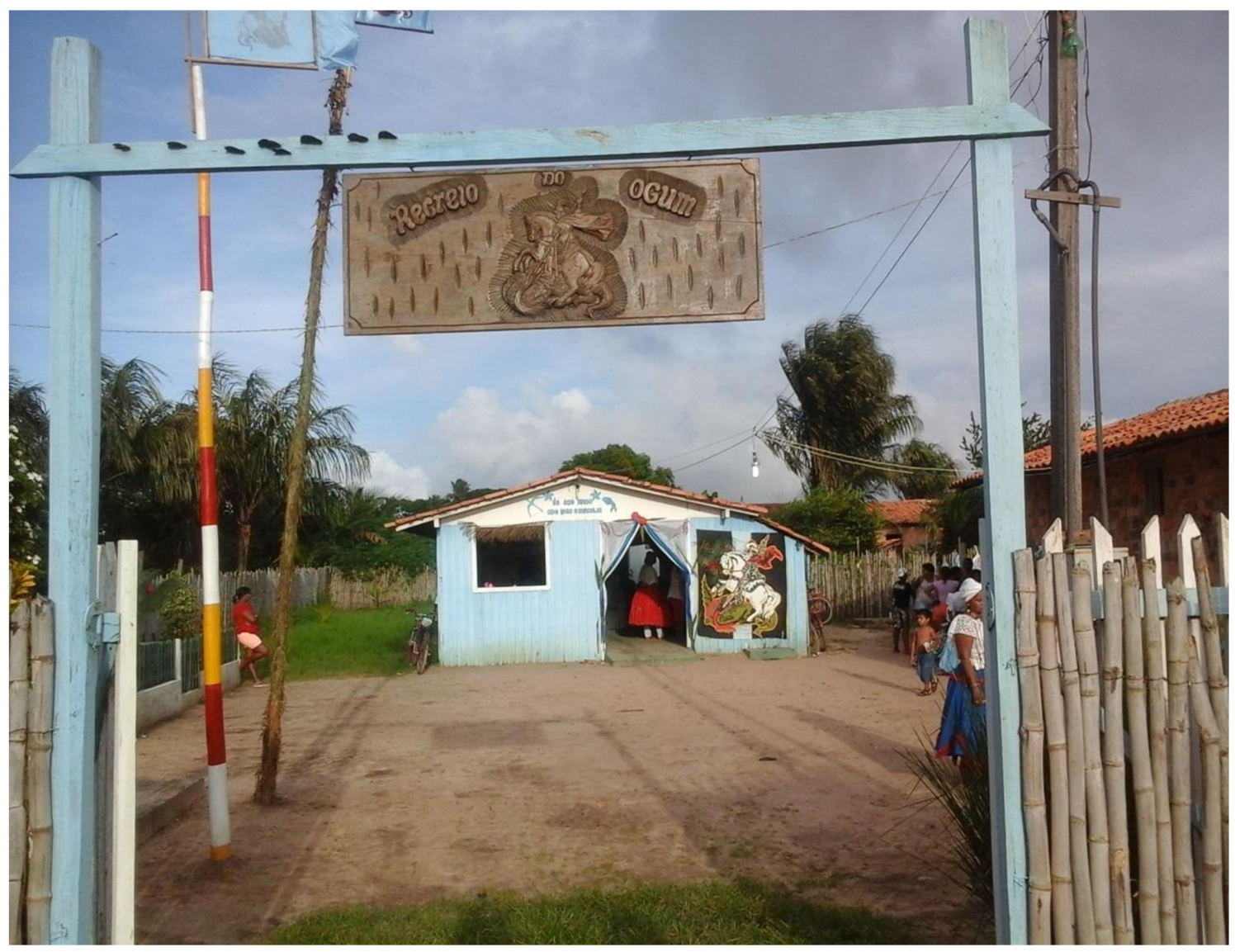




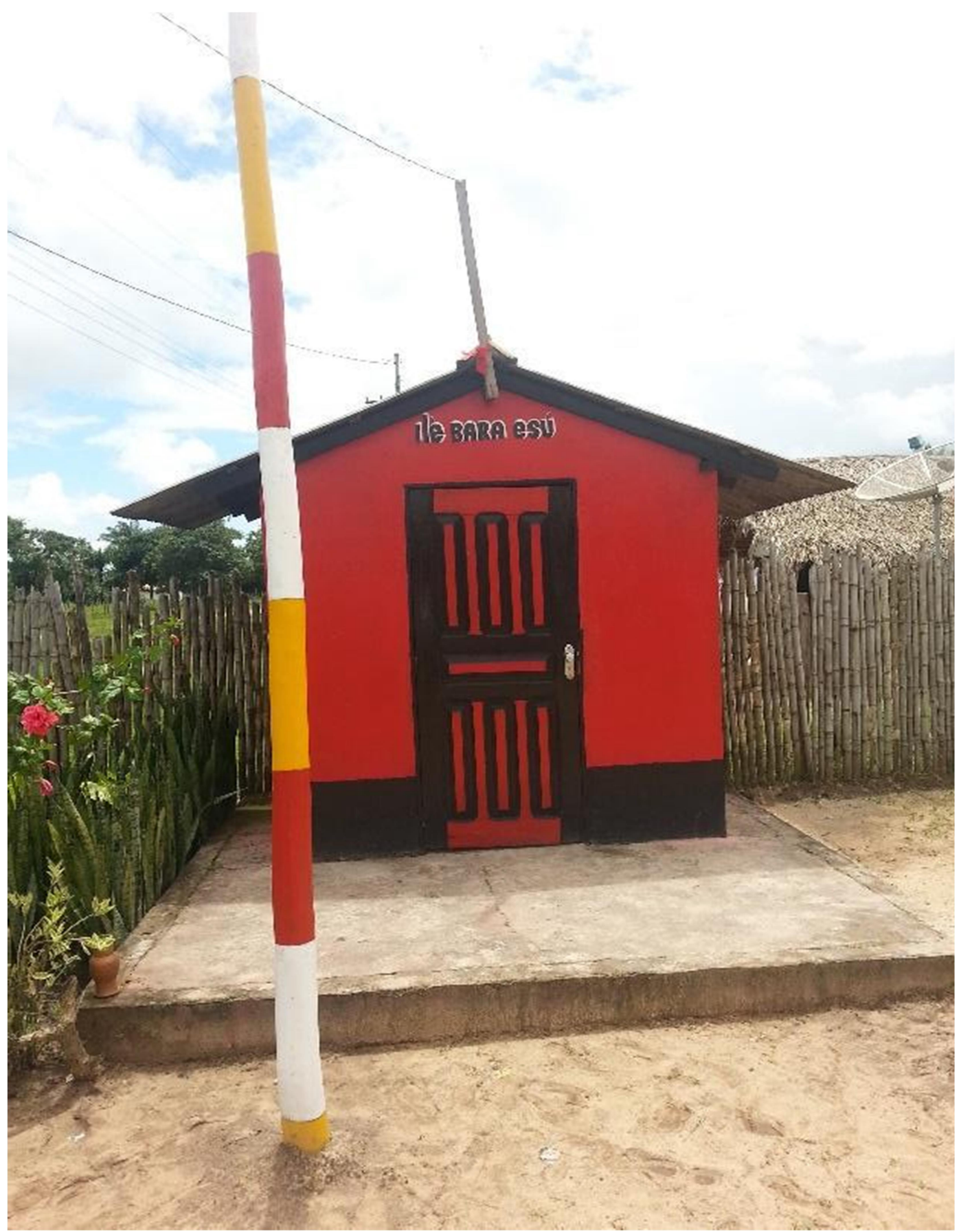



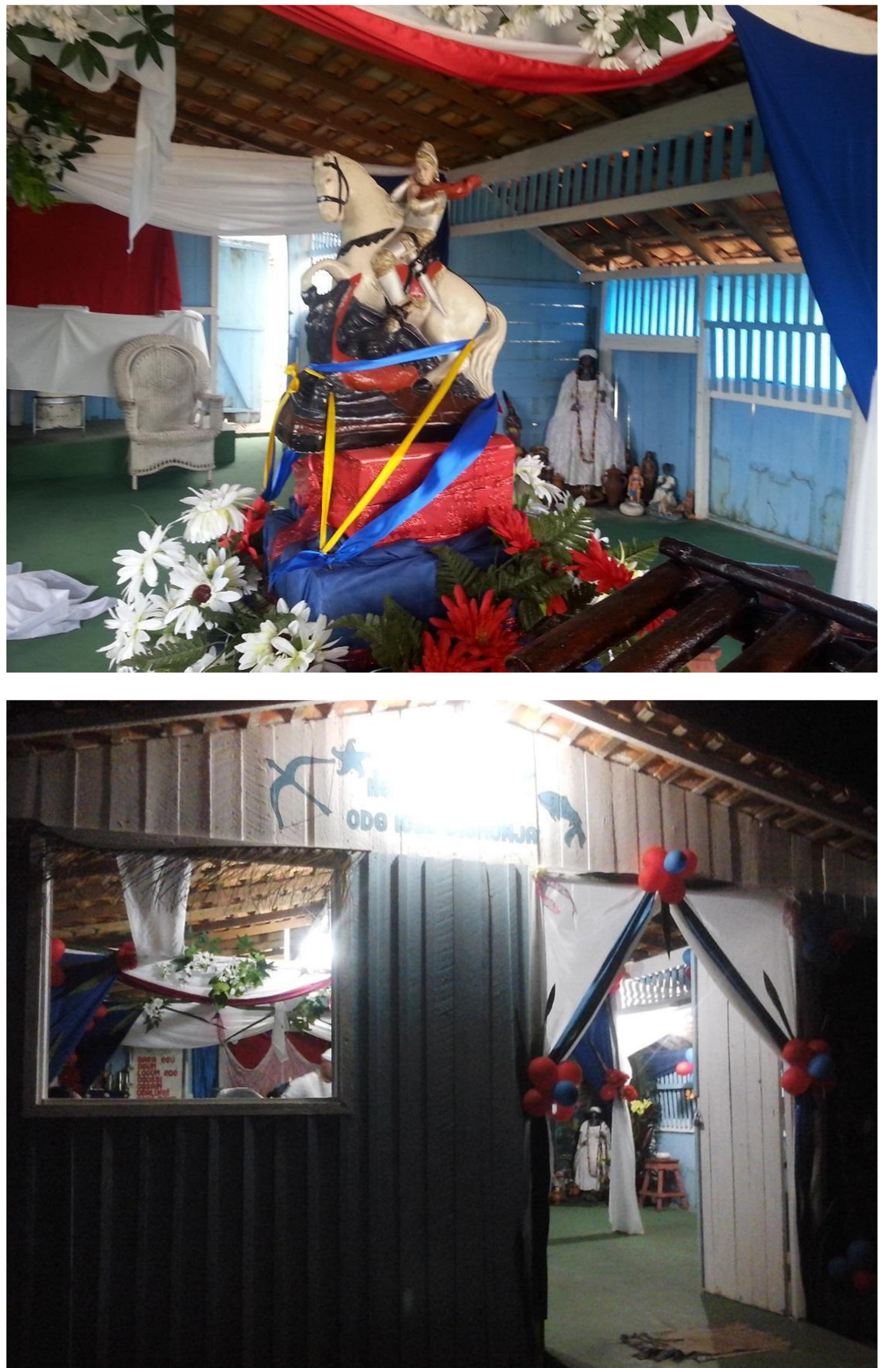


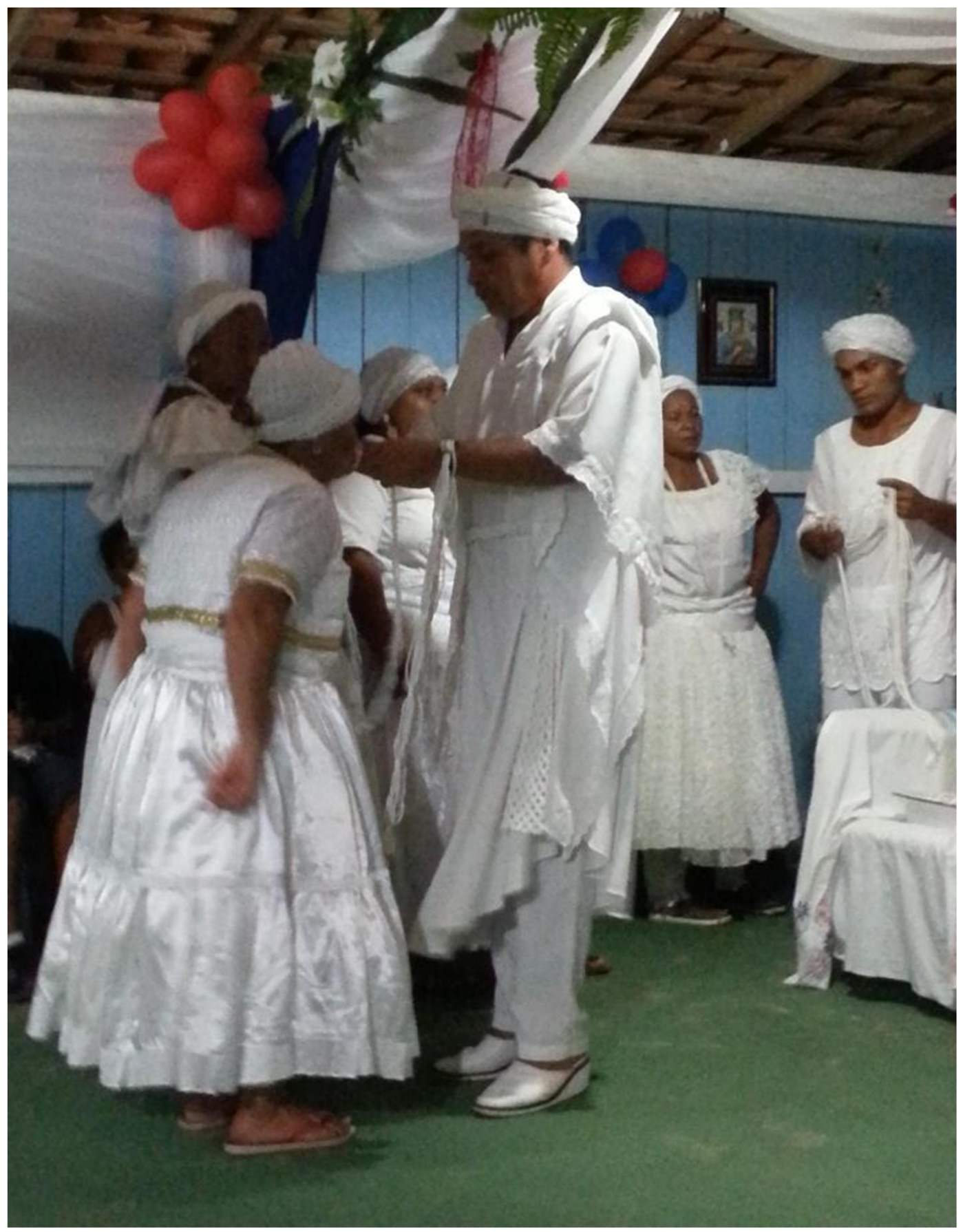




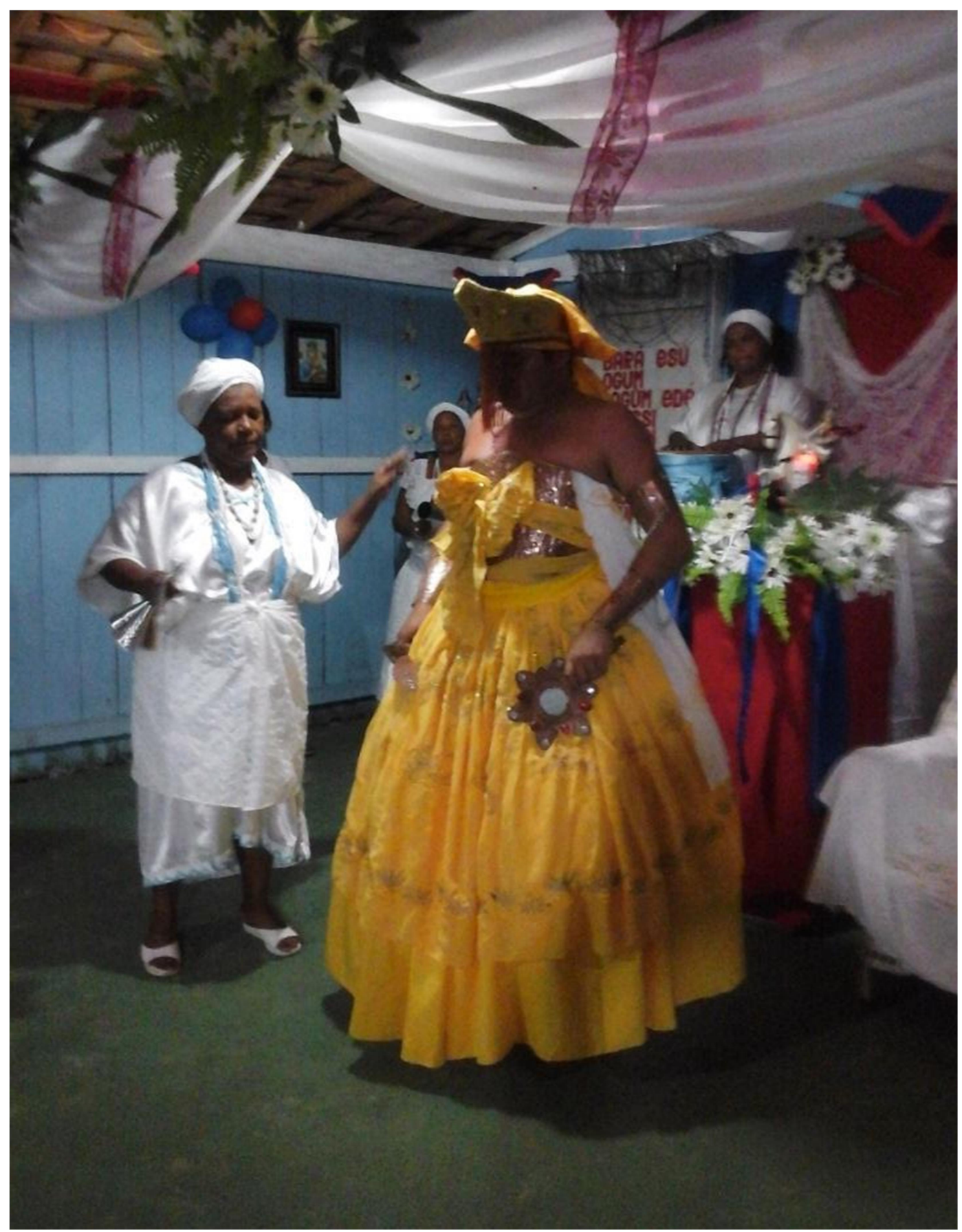




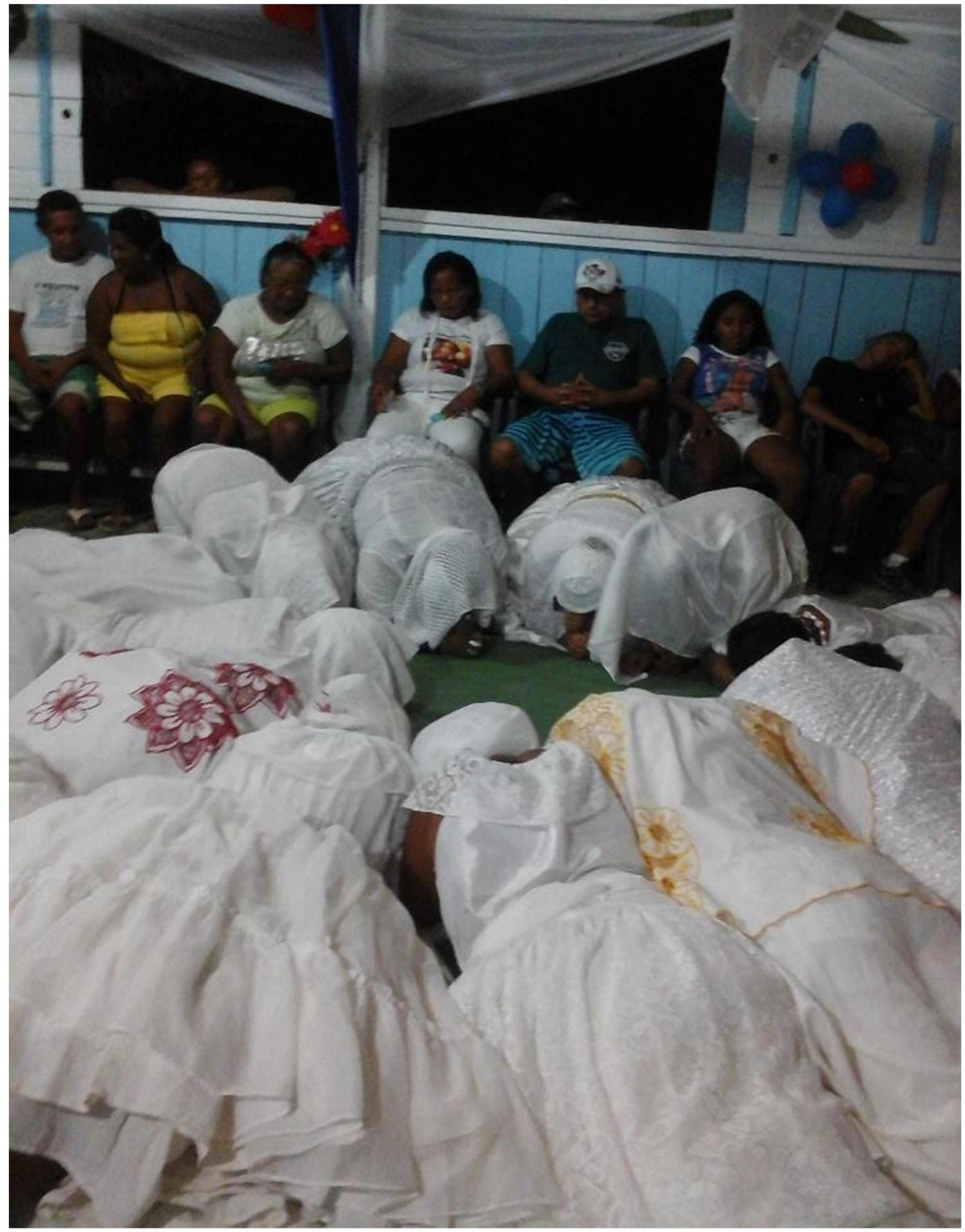




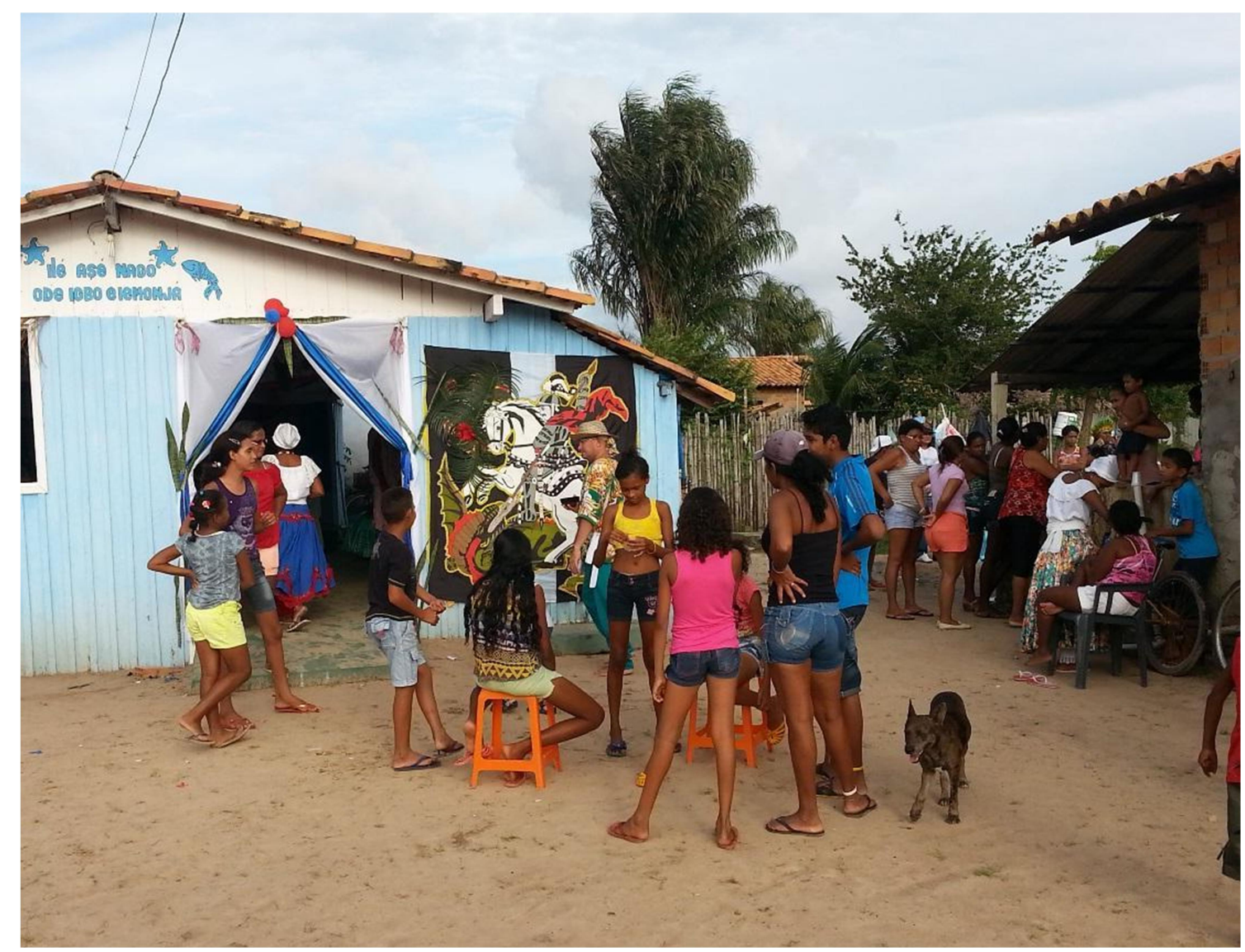




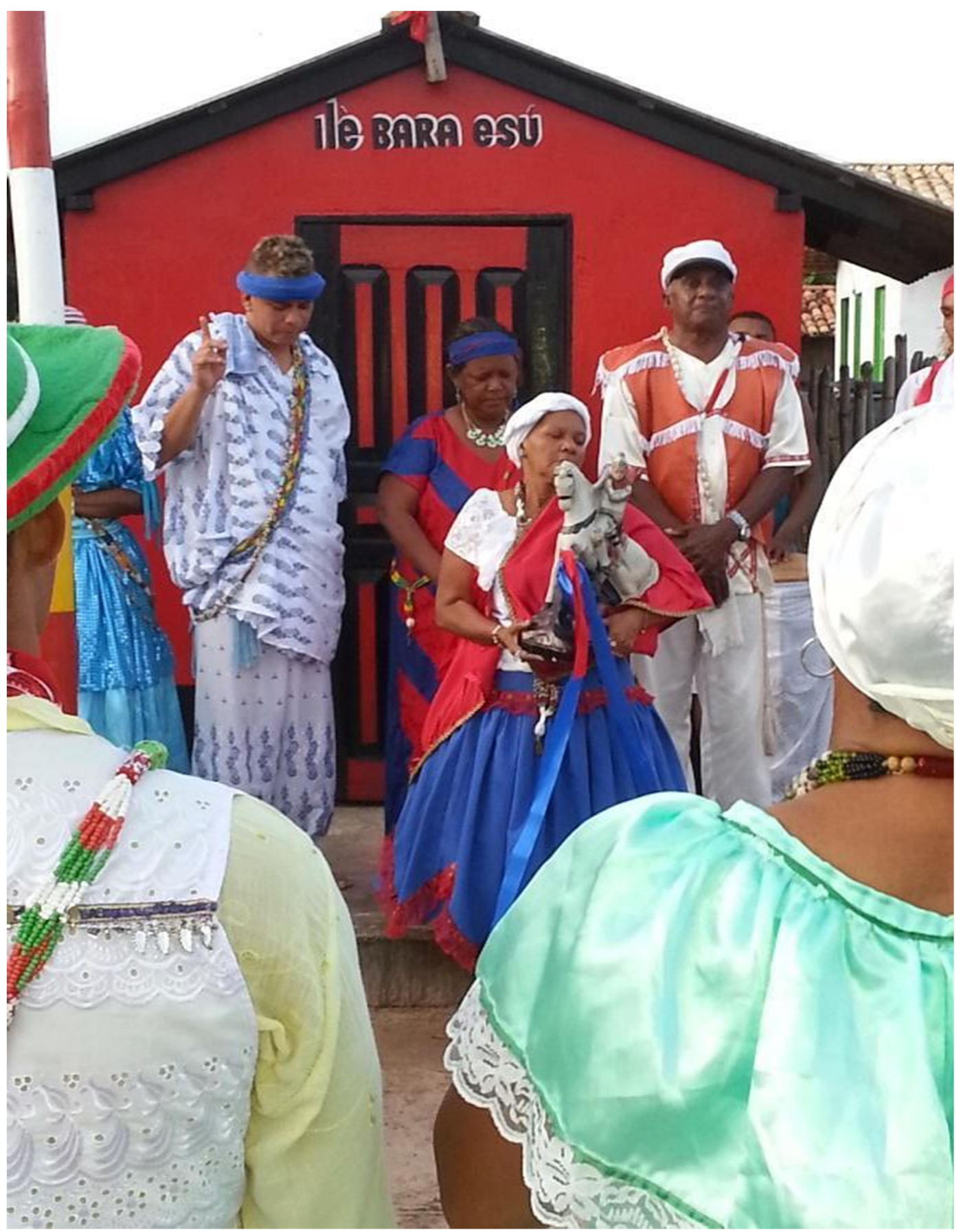




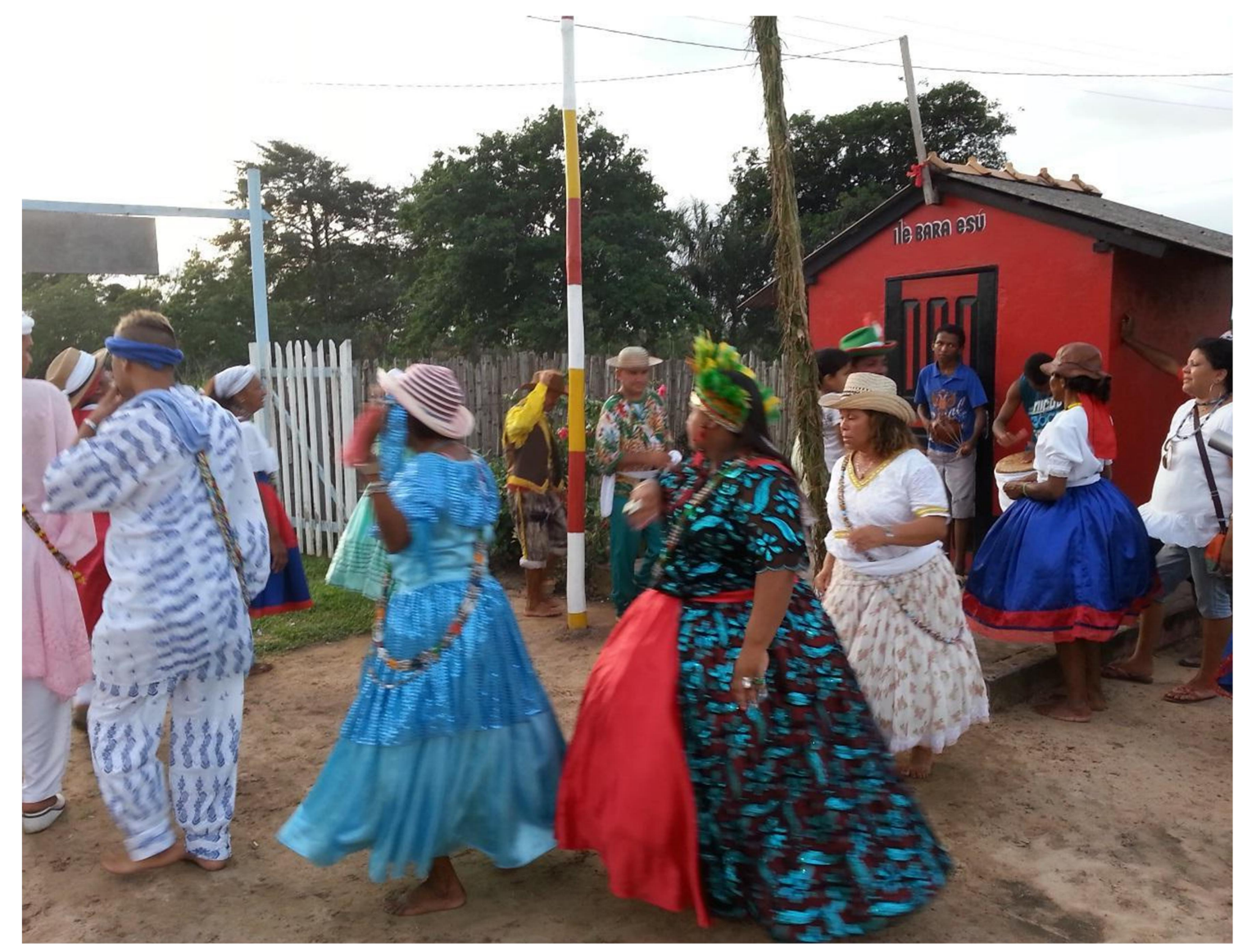

